\title{
Self-reported outcomes of patients undergoing total hip replacement surgery assessed by the WOMAC questionnaire
} Avaliação de resultados subjetivos de pacientes submetidos a artroplastia total de quadril pelo questionário WOMAC

\author{
Michele Ferreira de Souza Di Nubila ${ }^{1}$, Carolina Gomes Matarazzoํㅜㄹ Andrea Diniz Lopes-Albers ${ }^{1}$, \\ Fátima Cristina Martorano Gobbi ${ }^{1}$
}

\begin{abstract}
Objective: To assess pain, stiffness and physical function outcomes among patients undergoing total hip replacement using the Western Ontario and McMaster Universities Osteoarthritis Index. Methods: From January 2009 to July 2010, 64 male and female patients were assessed using the WOMAC questionnaire at baseline, hospital discharge, 3-month follow-up, and 6-month follow-up; one group of patients with primary hip osteoarthritis $(n=42)$ and another group with hip fracture $(n=22)$. Results: Changes in the total scores of the osteoarthritis group were statistically significant comparing baseline, hospital discharge, 3-month and 6-month assessments, demonstrating continued improvement over time up to 6-month follow-up. The total scores of the hip fracture group demonstrated a worsening from baseline to discharge, followed by improvement. The differences were statistically significant between baseline and discharge, as well as between discharge and the 6-month assessment. No statistically significant differences were found between baseline values and the 3-month assessment or baseline values and the 6-month assessment, demonstrating that the patients returned to their baseline health status after 3 months and maintained this status up to 6-month follow-up. Conclusion: The Western Ontario and McMaster Universities Osteoarthritis Index questionnaire detected changes in outcome following hip replacement surgery among patients with primary diagnoses of hip osteoarthritis and hip fracture, with differences in the pattern of changes between the two groups.
\end{abstract}

Keywords: Osteoarthritis; Hip fractures/surgery; Arthroplasty/methods; Arthroplasty, replacement, hip/rehabilitation; Questionnaires

\section{RESUMO}

Objetivo: Avaliar resultados referentes a dor, rigidez e função física de pacientes submetidos à artroplastia total de quadril utilizando o questionário Western Ontario and McMaster Universities
Osteoarthritis Index. Métodos: De Janeiro de 2009 a Julho de 2010, 64 pacientes homens e mulheres foram avaliados utilizando o questionário WOMAC no momento pré-operatório, na alta hospitalar, com 3 meses e 6 meses de seguimento; um grupo de pacientes com osteoartrite primária de quadril $(n=42)$ e outro grupo com fratura de quadril $(n=22)$. Resultados: Mudanças nos escores totais do grupo de osteoartrite foram estatisticamente significantes comparando-se a avaliações de pré-operatório, alta hospitalar, com 3 meses e 6 meses, demonstrando melhora contínua com o decorrer do tempo até o seguimento de 6 meses. 0s escores totais para o grupo com fratura de quadril demonstraram uma piora entre 0 momento pré-cirúrgico e a alta, seguida por uma melhora nos demais seguimentos. As diferenças foram estatisticamente significantes entre o pré-operatório e a alta, assim como entre a avaliação da alta e de 6 meses. Não houve diferença estatisticamente significante entre a avaliação pré-operatória e a de 3 meses ou entre a avaliação pré-operatória e a de 6 meses, demonstrando que os pacientes retornaram ao seu estado de saúde pré-cirúrgico após 3 meses, mantendo esse estado até 6 meses de seguimento. Conclusão: 0 questionário Western Ontario and McMaster Universities Osteoarthritis Index detectou mudanças após a cirurgia entre os pacientes com diagnóstico primário de osteoartrite de quadril e fratura de quadril, com diferenças nos padrões de mudança entre os dois grupos.

Descritores: Osteoartrite; Fraturas do quadri/cirurgia; Artroplastia/ métodos; Artroplastia de quadril/reabilitação; Questionários

\section{INTRODUCTION}

Total hip replacement (THR) is a surgical procedure for reconstruction of the hip for pain relief as well as improvement in physical function ${ }^{(1,2)}$. THR is indicated

\footnotetext{
Study carried out at Hospital Israelita Albert Einstein - HIAE, São Paulo (SP), Brazil.

${ }^{1}$ Hospital Israelita Albert Einstein - HIAE, São Paulo (SP), Brazil.

Corresponding author: Michele Ferreira de Souza Di Nubila - Avenida Albert Einstein, 627/701 - Morumbi - CEP: 05651-901 - São Paulo (SP), Brasil - Tel.: 11 2171-1100 - E-mail: michelefsdn@einstein.br

Received on: Feb 7, 2011 - Accepted on: Jun 27, 2011

Conflict of interest: none
} 
for patients with debilitating pain stemming from joint degeneration, in whom conservative treatment no longer produced results ${ }^{(1-4)}$. Osteoarthritis (OA), rheumatoid arthritis, avascular necrosis of the head of the femur, traumatic arthritis, lasting effects from a pathology that affected the hip in childhood, and unsuccessful prior surgical procedures are common causes of joint degeneration. THR is also recommended for patients with loss of functional independence for a previously active life after hip fracture ${ }^{(2,5-7)}$.

Pain relief is the major benefit of THR and its functional success leads to a significant improvement in quality of life ${ }^{(4,5,8-11)}$. As the physical exam is an insufficient indicator for functional, social, and emotional aspects, a number of questionnaires were designed to analyze health status, the impact of the disease, and the effectiveness of different treatments ${ }^{(12)}$.

The Western Ontario McMaster Osteoarthritis Index (WOMAC) is a multidimensional questionnaire used to assess pain, stiffness, and physical function among patients with OA of the hip or knee ${ }^{(13)}$. The WOMAC was translated and validated into different languages, including Portuguese ${ }^{(13)}$. As this questionnaire addresses symptoms and physical function among patients with hip conditions, it has also proven valid, reliable, and responsive for patients submitted to $\operatorname{THR}^{(12,14,15)}$.

\section{OBJECTIVE}

The aim of the present study was to assess data on pain, stiffness, and physical function outcomes among patients submitted to THR using the WOMAC questionnaire.

\section{METHODS}

This study was done with total hip replacement surgery patients at Hospital Albert Einstein, in the city of São Paulo, Brazil. The data of the present study (questionnaire) were obtained through a retrospective analysis of patient records. The WOMAC questionnaire is part of the evaluation protocol of total hip replacement surgery patients at the hospital.

Initially, data from a convenience sample of 64 male and female patients was assessed using the WOMAC questionnaire at baseline, hospital discharge, 3-month and 6-month follow-up, from January 2009 to July 2010. The data were recorded in the registry book and included in this present retrospective analysis; one group had primary OA of the hip $(n=42)$ and the other group, hip fracture $(n=22)$. Patients with cognitive and neurological disorders were excluded from the study.

The WOMAC questionnaire was administered through face-to-face interviews at baseline and at hospital discharge. At the 3-month and 6-month follow-up assessments, the WOMAC was administered through telephone interviews. The WOMAC is a multidimensional self-administered outcome measure designed for clinical trials involving patients with hip or knee OA. It probes the dimensions of pain (5 items), stiffness ( 2 items), and physical function (17 items) and has been recommended as an outcome measure for patients undergoing $\mathrm{THR}^{(12)}$. All items have the same weight and each has a score ranging from 0 to 4 . Each domain can be scored separately and the total score of the questionnaire ranges from 0 to 96 , for which 0 is the best and 96 is the worst score. In the present study, the mean values of the scores for each subscale (0-4) and the total score were used, since there were missing data that would affect the interpretation of the sum of the scores.

\section{Ethical considerations}

This study received approval from the local Ethics Committee under protocol number 1171-10 The committee considered unnecessary a specific informed consent for this study because the data used were retrospective data contained in the patient evaluation and all pieces of information were obtained from the hospital records.

\section{Statistical analysis}

Qualitative data were expressed as observed frequency and percentage values. Patient age was expressed as mean, standard deviation and range. The mean WOMAC scores for each group and time-point were expressed as mean and standard deviation. Comparisons between groups and time-points were performed using a mixed linear model, with an autoregression correlation structure and Bonferroni adjustments for multiple comparisons. All analyses were conducted with the SPSS software, version 17 (SPSS Inc., Chicago, IL, USA) and p-values less than 0.05 were considered statistically significant.

\section{RESULTS}

Table 1 displays the demographic and clinical characteristics of the sample $(n=64)$. Mean age was 69.46 years, ranging from 35 to 99 years.

There was a greater occurrence of primary OA of the hip $(n=42)$, followed by hip fracture $(n=22)$. Mean WOMAC scores and mean scores of pain, stiffness, and physical function subscales in $\mathrm{OA}$ and fracture groups are demonstrated in Figures 1 to 3. Mean and standard deviation of the mean of the total scores and 
Table 1. Baseline characteristics of the sample

\begin{tabular}{|c|c|c|c|c|c|c|}
\hline Characteristics & \multicolumn{2}{|c|}{$\begin{array}{c}\text { Total } \\
(n=64)\end{array}$} & \multicolumn{2}{|c|}{$\begin{array}{l}\text { Primary osteoarthritis } \\
\text { (n= } \mathrm{n}=\mathrm{42})\end{array}$} & \multicolumn{2}{|c|}{$\begin{array}{l}\text { Hip fracture } \\
\text { (n=22) }\end{array}$} \\
\hline Age (mean SD) & \multicolumn{2}{|c|}{$70.30(12.63)$} & \multicolumn{2}{|c|}{$66.21(11.99)$} & \multicolumn{2}{|c|}{$78.48(9.72)$} \\
\hline Range & \multicolumn{2}{|c|}{$35-99$} & \multicolumn{2}{|c|}{$35-86$} & \multicolumn{2}{|c|}{$57-99$} \\
\hline Missing data (n/\%) & \multicolumn{2}{|c|}{$1(1.6)$} & \multicolumn{2}{|c|}{$0(0.0)$} & \multicolumn{2}{|c|}{$1(4.5)$} \\
\hline Gender & $n$ & $\%$ & $n$ & $\%$ & $\mathrm{n}$ & $\%$ \\
\hline Female/male & $31 / 33$ & $48.4 / 51.6$ & $18 / 24$ & $42.9 / 57.1$ & 13/09 & $59.1 / 40.9$ \\
\hline \multicolumn{7}{|l|}{ Diagnosis } \\
\hline Primary osteoarthritis & 42 & $(65.6)$ & & & & \\
\hline Hip fracture & 22 & $(34.4)$ & & & & \\
\hline \multicolumn{7}{|l|}{ Prosthetic implant } \\
\hline Cementless & 35 & $(54.7)$ & 25 & $(59.5)$ & 10 & $(45.5)$ \\
\hline Cemented & 14 & $(21.9)$ & 9 & $(21.4)$ & 5 & $(22.7)$ \\
\hline Hybrid & 2 & (3.1) & 1 & $(2.4)$ & 1 & (4.5) \\
\hline Missing data & 13 & $(20.3)$ & 7 & $(16.7)$ & 6 & (27.3) \\
\hline
\end{tabular}

SD: standard deviation.

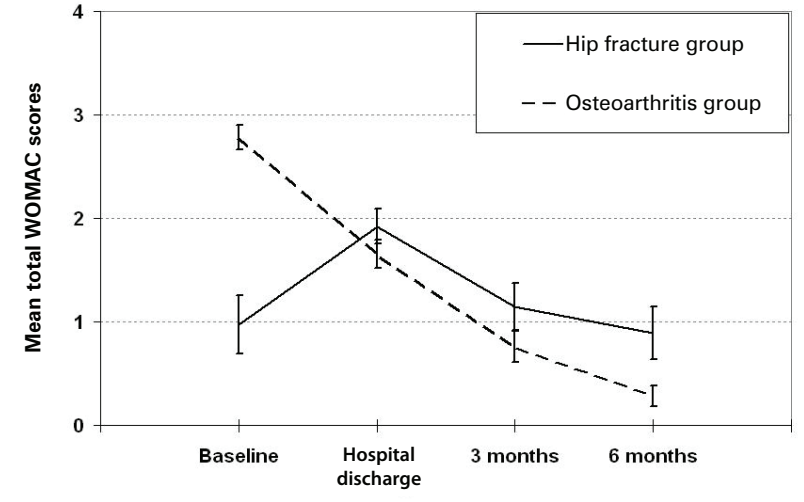

WOMAC: Western Ontario McMaster Osteoarthritis Index

Figure 1. Mean total WOMAC scores in osteoarthritis group $(\mathrm{n}=42)$ and hip fracture group $(n=22)$ at baseline, hospital discharge, 3-month follow-up and 6-month follow-up

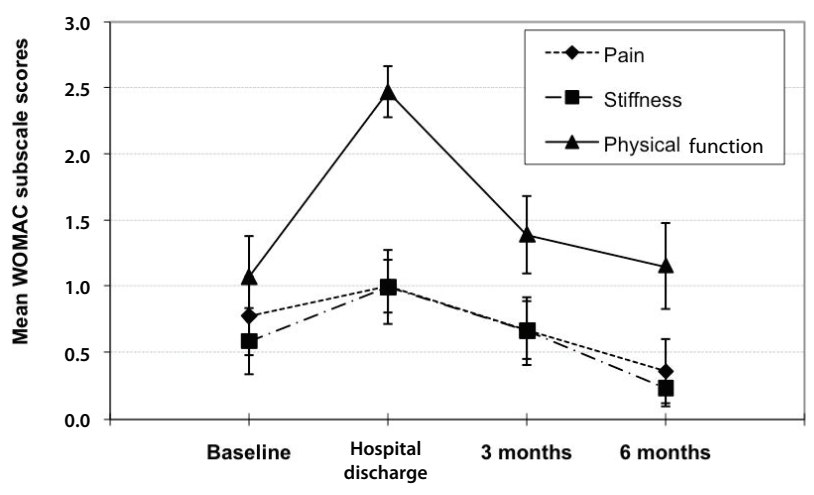

WOMAC: Western Ontario McMaster Osteoarthritis Index

Figure 3. Mean WOMAC subscale scores in hip fracture group $(n=22)$ at baseline, hospital discharge, 3 months and 6 months follow-up

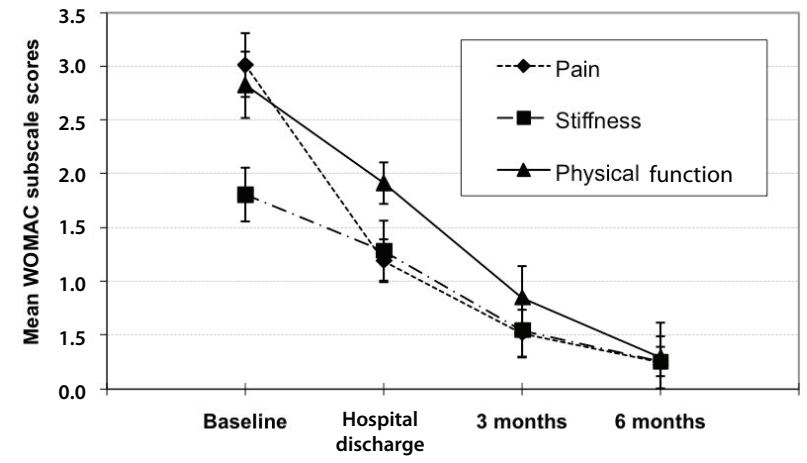

WOMAC: Western Ontario McMaster Osteoarthritis Index.

Figure 2. Mean WOMAC subscale scores in osteoarthritis group $(n=42)$ at baseline, hospital discharge, 3 months and 6 months follow-up

pain, stiffness, and physical function subscale scores are displayed on table 2 .

In the OA group, there was a reduction in the mean score after baseline (hospital discharge, 3-months follow-up, and 6-month follow-up) (Figures 1 and 2). Changes in the total score were statistically significant comparing baseline, hospital discharge, 3- and 6-month follow-up, demonstrating an improvement over time, which continued through to the 6-month follow-up (Table 2). The mean scores on the pain subscale revealed statistically significant changes comparing baseline with discharge, 3-month followup and 6-month follow-up. No statistically significant difference was found in pain between the 3-month and 6-month assessments (Table 2). 
Table 2. Mean, standard deviation and multiple comparisons of WOMAC total scores at baseline, hospital discharge, 3-month and 6-month follow-up in hip fracture group and osteoarthritis group

\begin{tabular}{|c|c|c|c|c|c|}
\hline \multirow{2}{*}{ WOMAC scores } & \multirow{2}{*}{ Group } & \multicolumn{4}{|c|}{ Timeframe } \\
\hline & & Baseline & Hospital discharge & 3 months & 6 months \\
\hline \multirow[t]{2}{*}{ Total scores } & Hip fracture & $0.97(0.28)$ & $1.92(0.17)^{*}$ & $1.15(0.22)$ & $0.89(0.26)^{\#}$ \\
\hline & Osteoarthritis & $2.78(0.12)^{\&}$ & $1.65(0.13)^{*}$ & $0.76(0.15)^{* \#}$ & $0.28(0.10)^{* \# \$}$ \\
\hline \multirow[t]{2}{*}{ Pain } & Hip fracture & $0.78(0.30)$ & $1.01(0.20)$ & $0.68(0.22)$ & $0.36(0.24)$ \\
\hline & Osteoarthritis & $3.01(0.15)^{8}$ & $1.19(0.17)^{*}$ & $0.52(0.17)^{*}$ & $0.25(0.15)^{* *}$ \\
\hline \multirow[t]{2}{*}{ Stiffness } & Hip fracture & $0.59(0.25)$ & $1.00(0.28)$ & $0.67(0.26)$ & $0.24(0.14)$ \\
\hline & Osteoarthritis & $1.81(0.26)^{8}$ & $1.29(0.21)$ & $0.55(0.15)^{* \#}$ & $0.26(0.12)^{* * \$}$ \\
\hline \multirow[t]{2}{*}{ Physical function } & Hip fracture & $1.08(0.31)$ & $2.47(0.19)^{*}$ & $1.39(0.29)^{\#}$ & $1.16(0.32)^{\#}$ \\
\hline & Osteoarthritis & $2.83(0.12)^{8}$ & $1.92(0.15)^{*}$ & $0.85(0.16)^{* \#}$ & $0.29(0.11)^{* \# \$}$ \\
\hline
\end{tabular}

Data described as mean (standard error).

${ }^{*} \mathrm{p}<0.05$ when compared to baseline; \# $\mathrm{p}<0.05$ when compared to hospital discharge;

${ }^{\$} p<0.05$ when compared to 3 -month follow-up; ${ }^{8} p<0.05$ when compared to hip fracture group;

$p<0.05$ : statistically significant difference.

WOMAC: Western Ontario McMaster Osteoarthritis Index

Statistically significant changes were found in the mean stiffness scores, except between baseline and discharge. There was a reduction in all mean physical function scores, with statistically significant improvements comparing baseline, hospital discharge, 3-month follow-up, and 6-month follow-up (Table 2).

The total scores of the hip fracture group demonstrated a worsening from baseline to discharge, followed by an improvement (Figure 1).

The differences were statistically significant from baseline to discharge as well as from discharge to the 6-month assessment (Table 2). No statistically significant differences were found between baseline and the 3-month assessment or baseline and the 6-month assessment, demonstrating that the patients returned to their baseline health status after 3 months, and maintained this status up to 6-month follow-up (Table 2). The subscale scores revealed more evident changes with regard to physical function (Figure 3), whereas no statistically significant changes were detected regarding pain and stiffness (Table 2).

Comparing data between groups (hip fracture and $\mathrm{OA}$ ), there were statistically significant differences at baseline in the total score and in the pain, stiffness, and physical function subscale scores. However, no differences were found at hospital discharge, 3-month follow-up, or 6-month follow-up (Table 2).

\section{DISCUSSION}

There was a greater occurrence of OA in the sample, followed by femur fracture. Such findings are frequently described in literature on $\operatorname{THR}^{(16-19)}$. The growing number of THR operations for patients with OA has accompanied the aging of the population ${ }^{(20)}$. OA causes pain and dysfunction, leading to a reduction in quality of life and patients experience an improvement soon after THR surgery ${ }^{(21)}$.

In the present study, significant changes in the WOMAC score were found in the group of OA patients following hospital discharge, demonstrating that patients experience improvement regarding pain, physical function, and stiffness immediately following surgery and that this improvement is progressive through to 6 months.

According to Jones et al., patients with total hip arthroplasty usually report significant pain relief within a week after surgery and the improvement achieves the greatest gain between 3 and 6 months following surgery, with the perception of a significant improvement in pain in the first week of the postoperative period ${ }^{(21)}$. According to the same authors, favorable gains reported for joint pain status following THR are well established in orthopedic literature ${ }^{(21)}$.

In the present study, there was no significant difference in the pain subscale between discharge and the 3-month assessment or between the 3-month and 6-month assessments, demonstrating that the improvement in pain was carried through to 6-month follow-up. A previous study reports similar WOMAC pain subscale scores at 3 and 6 months following THR surgery among patients with $\mathrm{OA}^{(22)}$.

Macaulay et al., on the other hand, demonstrate that the THR group can significantly improve the outcomes regarding pain and function after 2 years, suggesting that THA is a valuable treatment ${ }^{(19)}$. Nilsdotter and Isaksson showed in their prospective study that pain relief is excellent and independent of the baseline value, and that even 7 years after the operation, 97\% of the patients were satisfied with their pain relief and improved physical function ${ }^{(17)}$. 
There was also an improvement in stiffness in all assessment periods, with the exception of the comparison between baseline and discharge.

Groot et al. also reported statistically significant differences on the WOMAC stiffness subscale between the preoperative period, 3-month assessment, and 6-month assessment among patients with OA submitted to THR surgery, but did not compare stiffness between the preoperative period and discharge ${ }^{(22)}$.

The data on weight, height, and osteoarthritis could complement the results, but literature still has not determined a consensus among them. According to Reijman et al. there is no association with body mass index and progression of hip osteoarthritis ${ }^{(23)}$.

Statistically significant results were obtained regarding the physical function subscale at all evaluation time-points, demonstrating progressive improvement. Previous studies also reported a progressive improvement in function up to one year following surgery ${ }^{(17)}$. One prospective study on patients with OA submitted to THR surgery reported gain in physical function between 1 and 7 years following surgery, with no decline in the WOMAC score during this time ${ }^{(17)}$.

Literature also describes a considerable incidence of femur fractures. In the United States, for example, 350 thousand femur fractures occur every year and this incidence is expected to increase with the aging of the population $^{(19)}$. Moreover, studies involving patients with femur fractures treated with THR reported low rates of complications and revisions as well as improvements in physical function ${ }^{(19)}$. In the present study, the group with femur fractures had worse WOMAC scores at discharge in comparison to the preoperative period. According to Macaulay et al., there is a significant decline in function and independence following a femur fracture ${ }^{(16)}$. Comparing discharge to the 6-month assessment, there was an improvement in the WOMAC score, with scores at the 6-month assessment similar to those of the preoperative period (baseline), representing a return to the functional status prior to the trauma. This finding was more evident in the physical function subscale score. No significant differences were found between baseline, the 3-month assessment, and the 6-month assessment regarding pain and stiffness.

Comparing data between groups (hip fracture and $\mathrm{OA})$, there were statistically significant differences at baseline in the total WOMAC score and subscale scores. These findings suggest that these two groups of patients exhibit differences in functional status, stiffness, and pain. The clinical characteristics of these two conditions confirm this baseline difference. Patients with femur fracture experience a sudden loss of functional independence ${ }^{(16)}$. In contrast, patients with OA have a history of severe pain and progressive functional loss ${ }^{(17)}$.
In the current study, no differences were found between groups at discharge, at the 3-month assessment, or at the 6-month assessment, demonstrating that both groups exhibit a similar behavior regarding physical function, pain, and stiffness following surgery.

\section{CONCLUSIONS}

In conclusion, the WOMAC questionnaire detected changes in outcome in the short-term follow-up of patients who underwent hip replacement surgery due to hip OA and hip fractures, with differences in the pattern of changes between the two groups.

\section{ACKNOWLEDGMENTS}

We thank Natalia Penteriche de Almeida and Ana Paula Bezerra Leite for their support in data collection

\section{REFERENCES}

1. Harkess JW. Artroplastia do quadril. In: Crenshaw AH. Cirurgia Ortopédica de Campbel. São Paulo: Manole; 1996. p. 467-666.

2. Zimmerman JR. Artroplastia total de quadril e joelho. In: Turek. Tratado de medicina de reabilitação - princípios e prática. São Paulo: Manole; 2000. p. 1759-75.

3. Patrizzi LJ, Vilaça KHC, Takata ETT, Trigueiro G. Análise pré e pós-operatória da capacidade funcional e qualidade de vida de pacientes portadores de osteoartrose de quadril submetidos à artroplastia total. Rev Bras Reumatol. 2004;44(3):185-91.

4. Rudelli S, Aristide A, Viriato PS. Quadril do adulto. In: Hebert S, Xavier R, Pardini Jr AG, Barros Filho TEP. Ortopedia e traumatologia - princípios e prática. Porto Alegre: Artmed; 1998. p.203-24.

5. Peak EL, Parvizi J, Ciminiello, Purtill JJ, Sharkey PF, Hozack WJ, et al. The role of patient restrictions in reducing the prevalence of early dislocation following total hip arthroplasty. A randomized, prospective study. J Bone Joint Surg Am. 2005;87(2):247-53.

6. Lachiewicz PF, Soileau ES. Stability of total hip arthroplasty in patients 75 years or older. Clin Orthop Relat Res. 2002;(405):65-9.

7. Masonis JL, Bourne RB. Surgical approach, abductor function, and total hip arthroplasty dislocation. Clin Orthop Relat Res. 2002;(405):46-53.

8. Youm T, Maurer SG, Stuchin SA. Postoperative management after total hip and knee arthroplasty. J Arthroplasty. 2005;20(3):322-4.

9. Trudelle JE, Emerson R, Smith S. Outcomes of total hip arthroplasty: A study of patients one year postsurgery. J Orthop Sports Phys Ther. 2002;32(6):260-7.

10. Wang AW, Gilbey HJ, Ackland TR. Perioperative exercise programs improve early return of ambulatory function after total hip artroplasty. A randomized, controlled trial. Am J Phys Med Rehabil. 2002;81(11):801-6.

11. Quintana JM, Bilbao A, Escobar A, Azkarate J, Goenaga Jl. Decision trees for indication of total hip replacement on the patients with osteoarthritis. Rheumatology (0xford). 2009;48(11):1402-9.

12. Bachmeier CJM, March LM, Cross MJ, Lapsley HM, Tribe KL, Courtenay BG. A comparison of outcomes in osteoarthritis patients undergoing total hip and knee replacement surgery. Osteoarthritis Cartilage. 2001;9(2):137-46.

13. Fernandes Ml. Tradução e validação do questionário de qualidade de vida específico para osteoartrose WOMAC (Western Ontario McMaster Universities) para a língua portuguesa [tese]. São Paulo: Escola Paulista de Medicina da Universidade Federal de São Paulo; 2003. 
14. Jette AM, McDonough CM, Ni P, Haley SM, Hambleton RK, Olarsch S, et al. A functional difficulty and functional pain instrument for hip and knee osteoarthritis. Arthritis Res Ther. 2009;11(4):R107.

15. Gobbi FCM, Cavalheiro LV. Fisioterapia hospitalar - Avaliação e planejamento do tratamento fisioterapêutico. São Paulo: Atheneu; 2009.

16. Macaulay W, Nellans KW, lorio R, Garvin KL, Healy WL, Rosenwasser MP, et al. Total hip arthroplasty is less painful at months compared with hemiarthroplasty in the treatment of displaced femoral neck fracture. HSS J. 2008;4(1):48-54.

17. Nilsdotter AK, Isaksson F. Patient-relevant outcome 7 years after total hip replacement for OA - a prospective study. BMC Musculoskelet Disord. 2010;11:47.

18. Al-Taki MM, Masri BA, Duncan CP, Garbuz DS. Quality of life following proximal femoral replacement using a modular system in revision THA. Clin Orthop Relat Res. 2010;469(2):470-5.
19. Macaulay W, Nellans KW, Garvin KL, lorio R, Healy WL, Rosenwasser MP, et al. Prospective randomized clinical trial comparing hemiarthroplasty to total hip arthroplasty in the treatment of displaced femoral neck fractures - winner of the Dorr award. J Arthroplasty. 2008;23(6 Suppl 1):2-8.

20. Learmonth ID, Young C, Rorabeck C. The operation of the century: total hip replacement. Lancet. 2007;370(9597):1508-19.

21. Jones CA, Beaupre LA, Johnston DWC, Suarez-Almazor ME. Total joint arthroplasties: Current concepts of patient outcomes after surgery. Rheum Dis Clin N Am. 2007;33(1):71-86.

22. de Groot IB, Bussmann HJ, Stam HJ, Verhaar JA. Small increase of actual physical activity 6 months after total hip or knee arthroplasty. Clin Orthop Relat Res. 2008;466(9):2201-8.

23. Reijman M, Pols HA, Bergink AP, Hazes JM, Belo JN, Lievense AM, et al. Body mass index associate with onset and progression of osteoarthritis of the knee but not of the hip: The Rotterdam Study. Ann Rheum Dis. 2007;66(2):158-62. 